\title{
Urban Interiority in the Anthropocene
}

\begin{abstract}
This paper explores how interior design could amplify the current discourse on sustainability within urban public space. The consideration of a number of contemporary authors that are questioning the traditional notion of interiority situates this paper within an expansive understanding of interiority in the context of the Anthropocene. Interiority is considered as a transferable condition based on modes of interior occupation, that can take place on the outdoors, and is often found in public spaces within dense urban areas. In the face of an upcoming biodiversity crisis, this text advocates for a necessary disciplinary shift away from traditional anthropocentric views, towards a multispecies conception of the built environment. Both the ideas and the case studies in this article seek to expand the role of interior elements, both semiotics and performance, to foster inclusivity of non-human species, in particular insects, in city environments. Two design proposals illustrate how interior design tactics might positively contribute to raising awareness about this underacknowledged population, and at the same time, help cultivate a sense of intimacy between us and the multiple life forms that inhabit our public urban spaces.
\end{abstract}

Keywords: interior design, Anthropocene, urban interior, public space, inclusivity

Correspondence Address: Nerea Feliz Arrizabalaga, School of Architecture, The University of Texas at Austin, 310 Inner Campus Drive B7500, Austin, Texas 787121009. Email: nereafeliz@utexas.edu 


\section{Introduction: Interiority in the Anthropocene}

The notion of the Anthropocene, initially popularised by Nobel Laureate Paul Crutzen at the turn of the millennium, has progressively altered our perception of the world. The term provokes instant and acute awareness about the extent to which we, humans, have impacted the planet. Regarding disciplinary theory, from the current perspective of the Anthropocene, Buckminster Fuller's early understanding of Earth as a "mother-spaceship" can be related to contemporary philosopher Peter Sloterdijk's notion of our planet as a "grand interior," a constructed environment heavily manipulated by humanity. Looking back to the history of architecture, Sloterdijk (2014) considers the Crystal Palace as the turning point marking "the tendency to make both nature and culture indoor affairs" (p. 170). According to Sloterdijk (2014):

With its construction, the principle of the interior overstepped a critical boundary: from then on, it meant neither the middle- or upper class home nor its projection onto the sphere of urban shopping arcades; rather, it began to endow the outside world as a whole with a magical immanence transfigured by luxury and cosmopolitanism. (p. 170)

Today, several authors argue that the outdoors are just as manufactured as the indoors (Solomon, 2018). The Anthropocene has blurred the distinctions between natural and manmade. Almost half a century after Archizoom's No-Stop City was first published, contemporary designers such as Geers (2016) are openly declaring that "There is no outside anymore" that "we inhabit one giant interior" (p. 64). These authors are considering interiority as a ubiquitous and inescapable condition.

\section{Urban Interiority}

As a disciplinary framework in the Anthropocene, interiority is expansive and pervasive and becomes a space within which both architecture and urbanism operate. A general condition applicable to all space of public and private life in which atmospheric quality determines occupation and sets the stage for politics, interiority is increasingly the governing paradigm for urbanism in fast-growing cities and privatized suburban campuses alike. (Solomon, 2018, p. 419)

The analysis of contemporary urban dynamics and interior modes of occupancy in public space such as Solomon's (2018) analysis of public 
spaces in Hong Kong ${ }^{1}$ has informed an expansive understanding of interiority as a "condition" instead of a physical circumstance linked to shelter. According to Solomon (2018),

Indoor urbanism is not an urbanism of the indoors, but an urbanism in which indoors and outdoors no longer codify meaningful political or cultural distinctions in the city. In an interior urbanism, all space has equal potential to become part of a public or private sphere based on its occupation. (pp. 414-415)

In other words, public urban space can be understood as a network of indoor and outdoor spaces that merge into a modulated continuum. When we understand interiority as a condition linked to interior tactics of spatial appropriation, such as the use of furnishings, lighting, pavements etc., we also recognize that this condition can be temporary. A human-scaled interior condition can just "pop up" outdoors for a brief period of time, hours, days, or weeks (Adams \& Marlor, 2019). Outdoor restaurant seating areas, open-air amphitheatres for concert spaces, temporary markets etc. are examples of temporary interiority. Whether inside or outside, it is the calibration of spatial features at a human scale, atmospheric manipulation, the extent of people's appropriation of a given space, and the type of activities deployed, that determine a degree of "interiority." A novel conception of the urban interior has emerged, finally emancipated from architecture, that is not necessarily bound to the indoors, and that acknowledges the possibility of a transposed interiority based on models of interior occupation: not streets but corridors, not squares but rooms. Challenging the conventional distinction between interior and exterior, this reconceptualization of interiority is interrogating disciplinary boundaries, expanding theoretical approaches to the built environment and design practices. It is within this conceptual framework that the content of this paper is situated.

\section{Non-humans in the City: An Inclusive Urban Interiority}

At a global scale, the interiorisation of the environment carries with it some disturbing spatial implications regarding selective inclusion and exclusion of species. Farming and agriculture support a small selection of species to the detriment of all others. At the same time, we are all aware of how exhaustive urbanisation drastically decreases biodiversity in cities by eliminating the habitats of

\footnotetext{
${ }^{1}$ Quotes from Solomon (2018) are linked to the author's analysis of Hong Kong network of public spaces. See also the previous volume in this journal, particularly Adams \& Marlor (2019), analysis of markets and train stations in the UK.
} 
most native species. Additionally, the environmental damage of urbanisation takes a significantly longer time to recover from than that of agriculture. The Anthropocene has dramatically made apparent the dominant position of humans towards other species. A recent study estimates that $96 \%$ of all mammals currently on the planet are either humans or livestock (Bar-On, Phillips, \& Milo, 2017, in Carrington, 2019). Seventy percent of all birds on Earth are chickens and other poultry raised for human consumption. Parallel to climate change, experts foresee an incipient biodiversity crisis marking the beginning of a huge loss of species on Earth. "Sixth mass extinction" is the term utilised by scientists to refer to the next vast annihilation of wildlife. ${ }^{2}$

In the context of urban space, from our anthropocentric perspective, the notion of "city life" typically signifies the vitality of human life, but rarely does it evoke the idea of "life" more holistically, as a web of diverse and interdependent species. While we often think of cities as human territory, the reality is that they are home to a multiplicity of life forms. Among the most plentiful and diverse living populations in cities are insects and arthropods. According to a number of recent studies (Carrington, 2019), 40\% of insect species are in danger of extinction in the coming decades. This is eight times faster than the rate of extinction of other species. Butterflies and moths are among the most endangered. Intensive agriculture, specifically the extensive use of pesticides, is the main cause of the decline of this population; however, climate change and urbanisation also play an important role. Insects constitute over $80 \%$ of the world's species population but often elude visible recognition.

In urban environments, insects are a significant part of the ecosystem. Various insect species are bioindicators, or "living barometers" of environmental conditions. They are pollinators, seed dispersers, decomposers, and serve as a food source for other species such as bats, birds, reptiles, amphibians and fish. In the absence of insects, some of these other species will also be endangered. While insects have conventionally been considered undesirable pests within densely populated areas, this perception is slowly starting to change. Joyce Hwang (2013) urges us to reexamine our preconception of the "pest" to avoid intensifying the ecological crises that we are experiencing.

When it comes to sustainability within architecture's disciplinary sphere, most common concerns and efforts focus on using renewable energy and resources and limiting energy consumption

\footnotetext{
${ }^{2}$ Previous ones were due to meteorite impacts, long ice ages etc.; this one is the result of humanity's actions.
} 
through a greater understanding of materials' embodied energy, construction methods and reducing a building's operational carbon footprint. In the face of an incoming biodiversity crisis, design disciplines linked to the built environment, which have traditionally exhibited an exclusively anthropocentric focus, are increasingly aware of the need to actively engage in protecting biodiversity in urban environments. When dealing with insects specifically, in recent years we have witnessed the appearance of insect hotels and bee corridors in cities. In the heart of London for example, a number of insect hotels have been placed in Russell Square Gardens, while a seven-mile-long wildflower corridor is being planted to boost bee populations in the north of the city. Also, a recent design competition for insect hotels culminated in five winning designs by leading architecture offices, including major corporate office Arup, which were built in five different parks in London (Meinhold, 2010).

While the examples above portray how the inclusion of insect habitats and contemporary landscape design practices can foster the presence of insects in urban environments, this paper seeks to consider how interior design practices can also contribute and engage with the dialogue surrounding this pressing global crisis. Among the few precedents found within interior design, the work by Kaltenbach Lab stands out as a research platform engaged with "research, provocation and speculation centered on the relationship between design and insects" (Kaltenbach, 2014). Most workshops, projects and publications lead by Christopher Kaltenbach, centre around "structures, products and services derived from insects used in biotechnology, food/product production and as pets" (Kaltenbach, 2014). Aside from Kaltenbach broad interest in insect's biotechnology and biomimicry, the Insectarium research facility located on the NSCAD University campus, provides a very unique example of a design intervention that seeks to integrate terrariums for life crickets, silkworms and beetles inside a 19th-century building. Inspired by the micron level structural characteristics found in the exoskeletons of many insect wings, the design is constructed with 384 hexagonal cardboard tubes (the terrariums hosting the insects) stacked into a three-dimensional surface (Kaltenbach, 2016). It is the integration of insects within an interior environment which make this project a key design example of an inclusive understanding of the built environment that welcomes the presence of insects.

The next two projects apply interior design as a material expression of social and cultural values which can take a proactive stance towards the integration of other species within urban environments. Global climate as a challenge is not just scientific and technological, but also cultural and political. In the realm of public space, design, 
as a time-specific intervention and communication device, can help amplify current discourse on climate change. The second half of this article describes two experimental projects designed by Double Happiness $^{3}$ that aim to bring awareness to various forms or urban "life" and support an inclusive web of interdependent species, both human and non-human. The proposals foster inclusivity of nonhuman species, especially insects, in city environments. Regular consultation with experts including environmental engineers, entomologists, botanists and pedologists informed the design propositions. The following projects seek to interrogate and expand the role, both semiotics and performance, of conventional interior elements, such as colour, curtains, benches and lighting, in the hope that interior design tactics in the context of public urban space might also contribute to cultivating environmental awareness and a sense of urban intimacy between us, and other life forms that inhabit the city, fostering respect, curiosity and even admiration toward the under-acknowledged world of insects.

Figure 1

City Creatures, axonometric view, daytime

(Image by

Double Happiness)

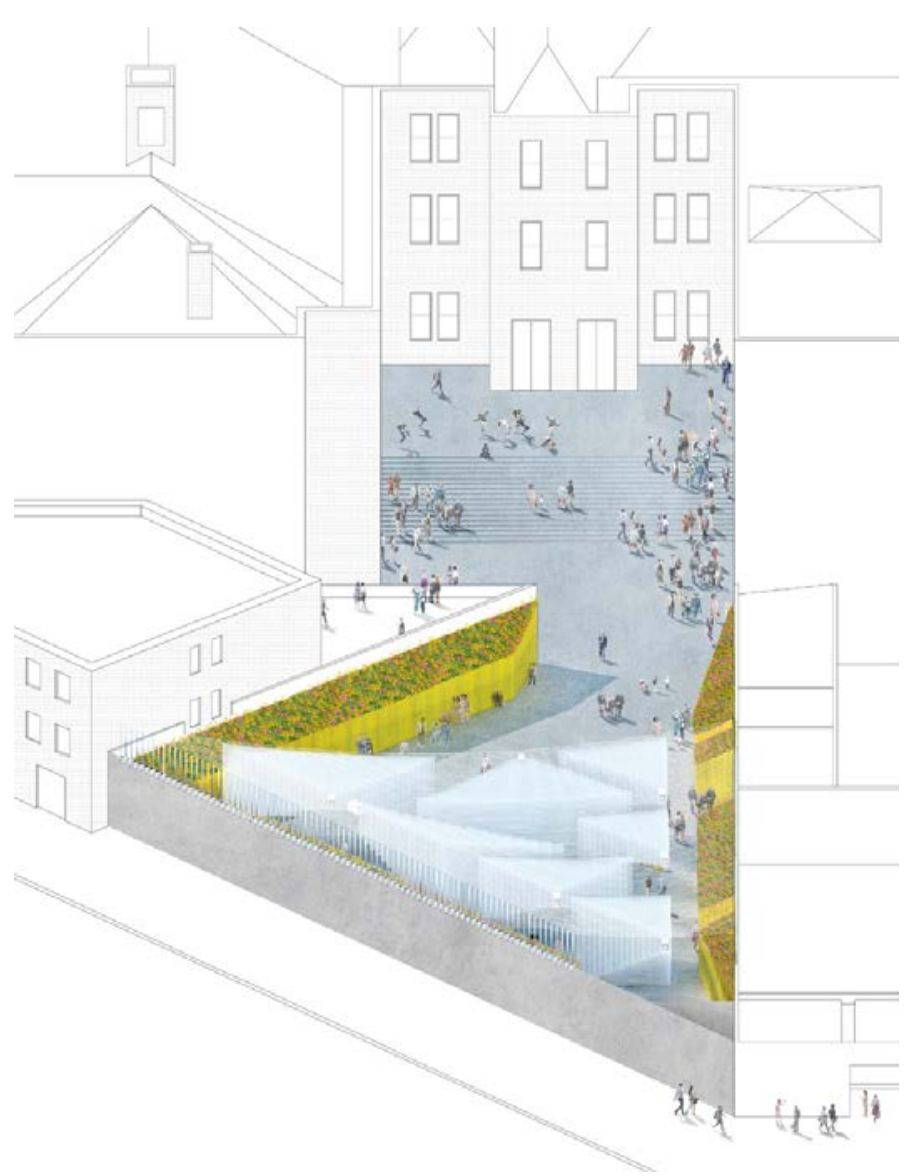

${ }^{3}$ Double Happiness is a collaboration between the author Nerea Feliz (Nerea Feliz Studio) and Joyce Hwang (Ants of the Prairie). As a team, Nerea and Joyce bring together interests in exploring design as a proactive participant in the environment, and a reflection of socio-cultural values through material expression. 


\section{Project 1: City Creatures}

City Creatures was the outcome of a nomination to participate in the 2019 invited PS1 MoMA Summer Pavillion competition. ${ }^{4}$ Looking at MoMA PS1 courtyard as an outdoor room, this unbuilt competition entry uses traditional elements of the interior: curtains, to produce a sense of public interiority. Recent research shows that in New York City, insects compete with rats as waste scavengersnot only keeping the rodent population from increasing, but also performing ecosystem services as 'waste managers.' City Creatures seeks to make visible the under-acknowledged world of insects as active participants of urban life, by attracting and magnifying their presence in our urban spaces.

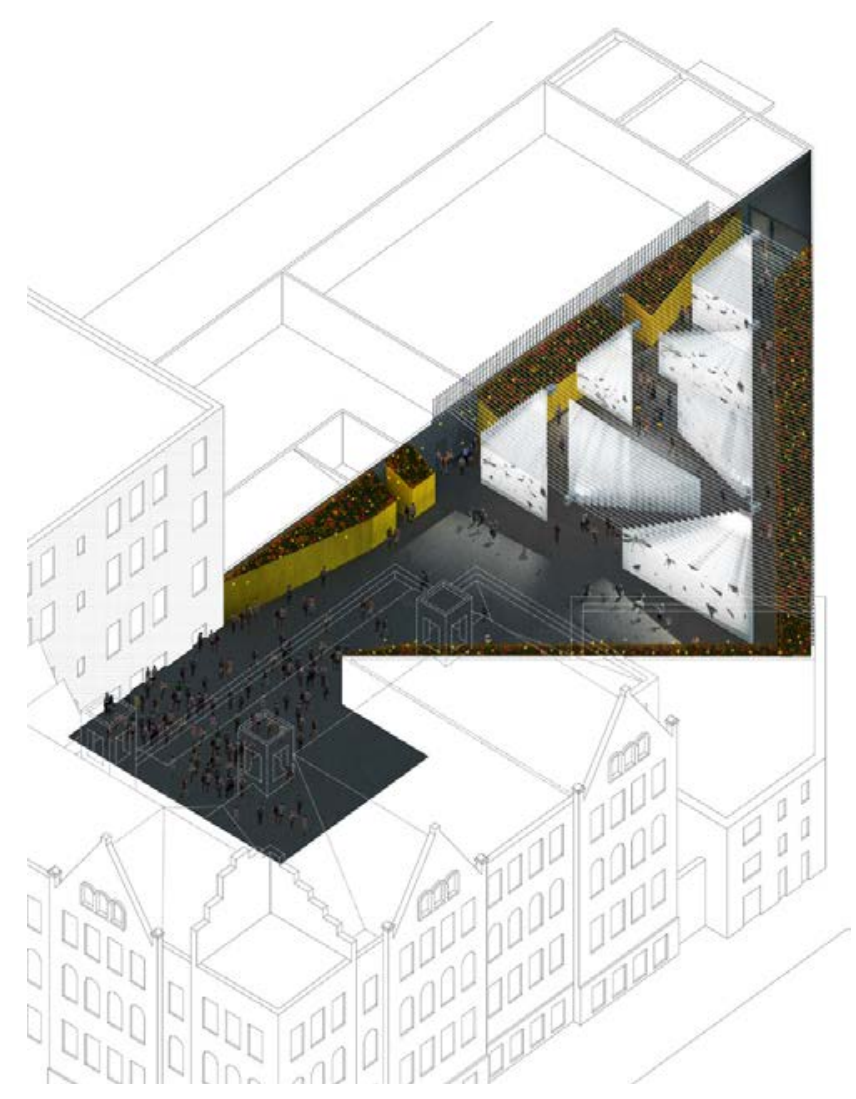

Figure 2

City Creatures, axonometric view, nighttime (Image by Double Happiness)

To cultivate a selected insect habitat, the project incorporates an elevated garden along the perimeter of the main courtyard. Wildflowers would attract a variety of pollinators, including fireflies, ladybugs, bees, butterflies, and hummingbirds. Milkweed, for example, is essential for Monarch Butterflies, as it serves as both breeding grounds for eggs and a food source for Monarch caterpillars.

${ }^{4}$ City Creatures is a project by Double Happiness. Project assistants: Hannah Frossard and Bruno Canales. 
New York City is located along the spectacular 3000-mile migratory route of the Monarchs, which are visible in late spring and summer. Raised planting beds give heightened visibility to this ecosystem, while also inhibiting direct contact between insects and people, which would drive off certain species such as butterflies. A golden corrugated metal wall is designed as a light plane to conceal a basic structure elevating the planters, an irrigation system, and storage. The golden hue attracts certain insect species and boosts the presence of the garden in the courtyard. The wall undulation dialogues with the natural wave of the scrims. Its golden reflectivity provides a festive backdrop, enlivening the atmosphere of the PS1 courtyard.

Figures $3 a-3 b$ City Creatures, nighttime perspective, life projections attracting insects and moths (Image by Double Happiness)

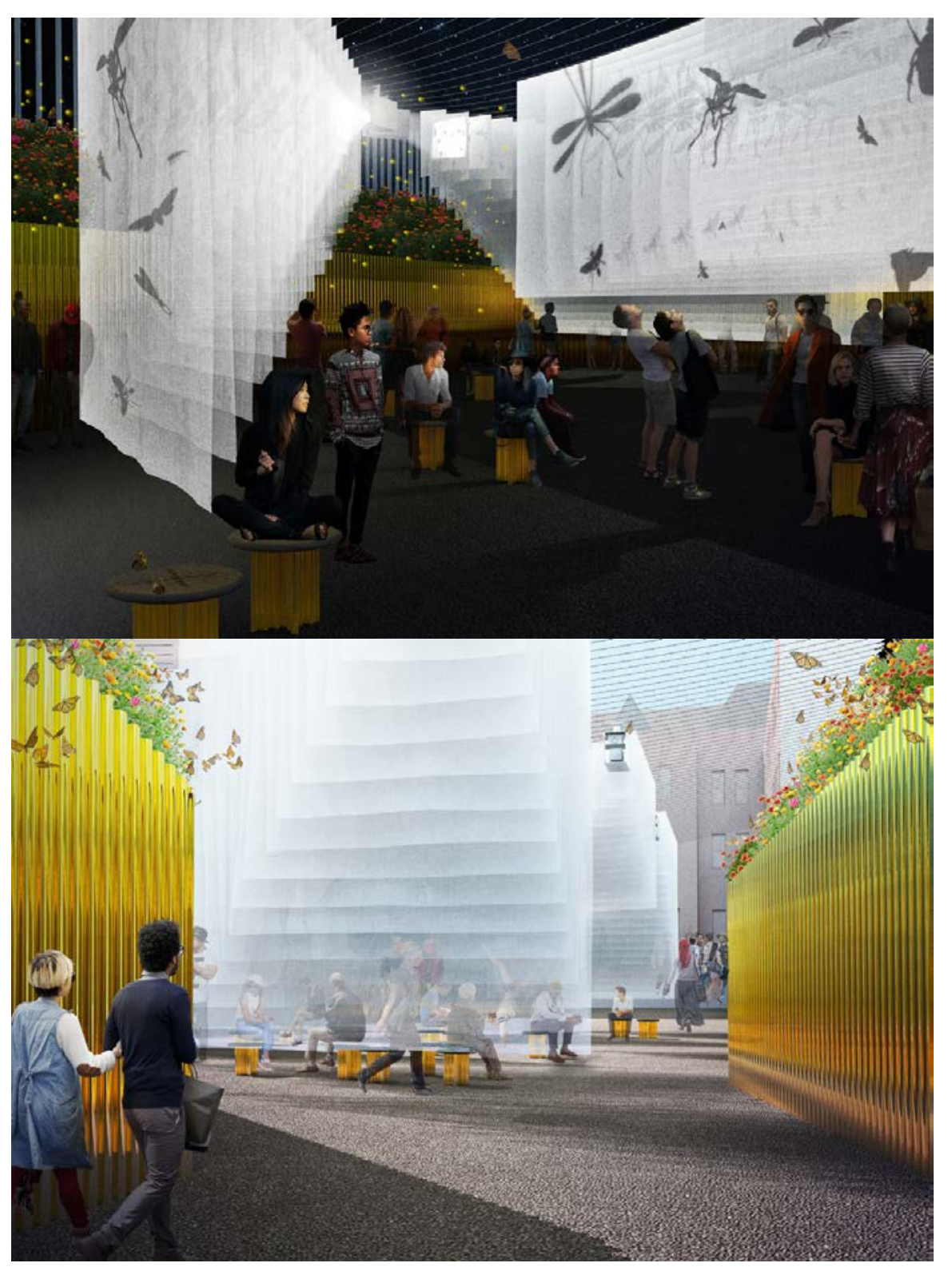


After sunset, the design uses "positive phototaxis," or the tendency for insects to be attracted to artificial light sources. A series of curtains, constructed from mosquito netting fabric, are hung from catenary cables spanning the MoMA PS1 courtyard. Located the end of each series of layered curtains, an artificial light source would be employed to both attract insects and cast their shadows on the hanging scrims, which would also filter and reflect the light to produce an ephemeral glow. Pre-recorded documentation of insects could also be projected through the layers of scrims against one that is playing out in real time. Against the monochromatic backdrop of mosquito netting, the visualisation of insects-whether through projected shadows or video-becomes a form of both spectacle and awareness-raising, an immersive insect shadow play bringing the space to life. During the day, the hovering curtains provide shade and transform the courtyard into a softer and interiorised urban condition. At the end of the installation, the mosquito nets could be donated to one of many humanitarian organisations combating malaria. City Creatures deploys light projections on curtains to both attract insects, while also provoking human curiosity through a new spatial and perceptual experience, where the PS1 courtyard is transformed into an interior environment that celebrates the many species that inhabit the city.

\section{Project 2: Hidden in Plain Sight}

Hidden in Plain Sight ${ }^{5}$ is a proposal for a series of urban furnishings doubling as multi-species infrastructures in the city. Fostering coexistence between humans and non-human species, this body of research is part of a multi-year initiative to turn the outdoor courtyard of Matadero, a cultural centre in Madrid, Spain into a laboratory for testing nature-based solutions that increase the resilience of this public space towards climate change. ${ }^{6}$ During the design process, the team participated in a series of monthly interdisciplinary workshops with representatives from the Madrid City Council, as well as scientists and experts from the Universidad Politecnica de Madrid.

\footnotetext{
${ }^{5}$ Hidden in Plain Sight is a project by Double Happiness. Project assistants: Robert Anderson, Hailey Brown, Raymond Castro, Richard Gagle, Gabriel Gatica, Francisco Resendiz Carrill, Sara Svisco, Zach Fields, Sasson Rafailov.

6 Hidden in Plain Sight is part of a collective Cyborg Garden proposal comprised of works by a selected group of artists. The Cyborg Garden project is directed by Matadero Medrid and curated by elii [architecture office] as part of a broader initiative from Matadero Mutant Action. Hidden in Plain Sight was presented as part of the Cyborg Garden and Eco-visionaries exhibition that took place at Matadero Madrid from 14 June to 6 October 2019.
} 
To support and cultivate beneficial insect populations, the project identified some local butterflies and moth species. The prototypes are designed as supportive habitats for caterpillars and butterflies. Entomologists ${ }^{8}$ helped identify the specific local plants that attract both caterpillars and butterflies, as their diet significantly changes as they mature. Gardens, filled with nutritious plants for caterpillars, such as arugula and Brussels sprouts, are mesh-enclosed to protect them from predators. The mesh also prevents human visitors from coming into contact with stinging nettle and other plants that are beneficial to caterpillars, yet potentially irritating to humans. Open planting beds house brightly-coloured wildflowers specially curated to attract nectar-seeking butterflies.

Figure $4 a-4 b$

Perspectives of urban furnishings within Matadero

Madrid public spaces (Images by Double Happiness)

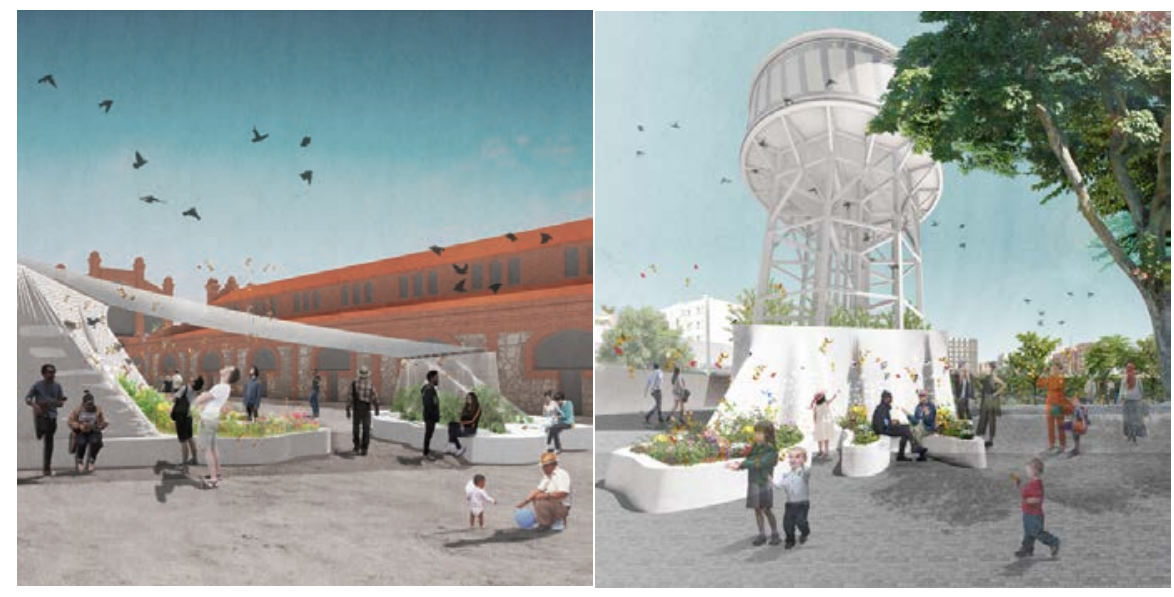

In dense cities like Madrid, urban interiors form a network of public spaces that are both indoor and outdoor. Hidden in Plain Sight is conceived of a series of urban furnishings that improve the quality of these public spaces by providing seating, lighting, shade, and vegetation. This family of prototypes operate between and across scales-from the scale of humans to the scale of the insect. A series of urban rooms, walls, and furniture can function as individual units or in aggregation - setting the stage for public programming, such as film screenings and small concerts.

\footnotetext{
${ }^{7}$ Blanca del Majuelo, Blanca de la Col, Chupaleche, Macaon, Grand Pavon de Noche, Gitana, Ortiguera, Limonera, Vanesa and Esfinge Calavera.

${ }^{8}$ Ecology consultants consist of: Rafael Ruiz López de la Cova (Departamento de Cambio Climático, D.G. Sostenibilidad y Control Ambiental, Área de Medio Ambiente y Movilidad. Ayuntamiento de Madrid), Francisco Jose Cabrero (Biodiversidad, Ecología y Evolución, Facultad de Biología, Universidad Complutense de Madrid), Dr. José I. Aguirre (Biodiversidad, Ecología y Evolución, Facultad de Biología, Universidad Complutense de Madrid), and José Luis Yela García (Profesor Titular de Zoología y Conservación Biológica, Universidad de Castilla-La Mancha).
} 


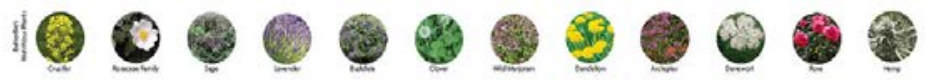

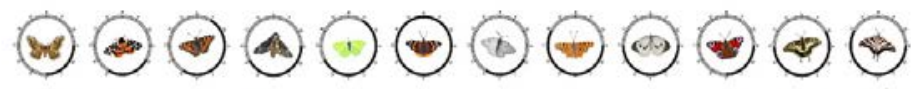

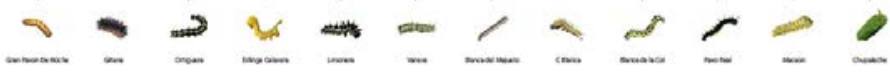

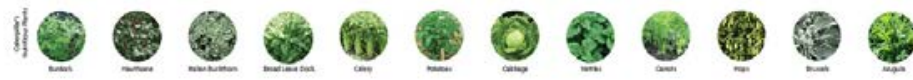

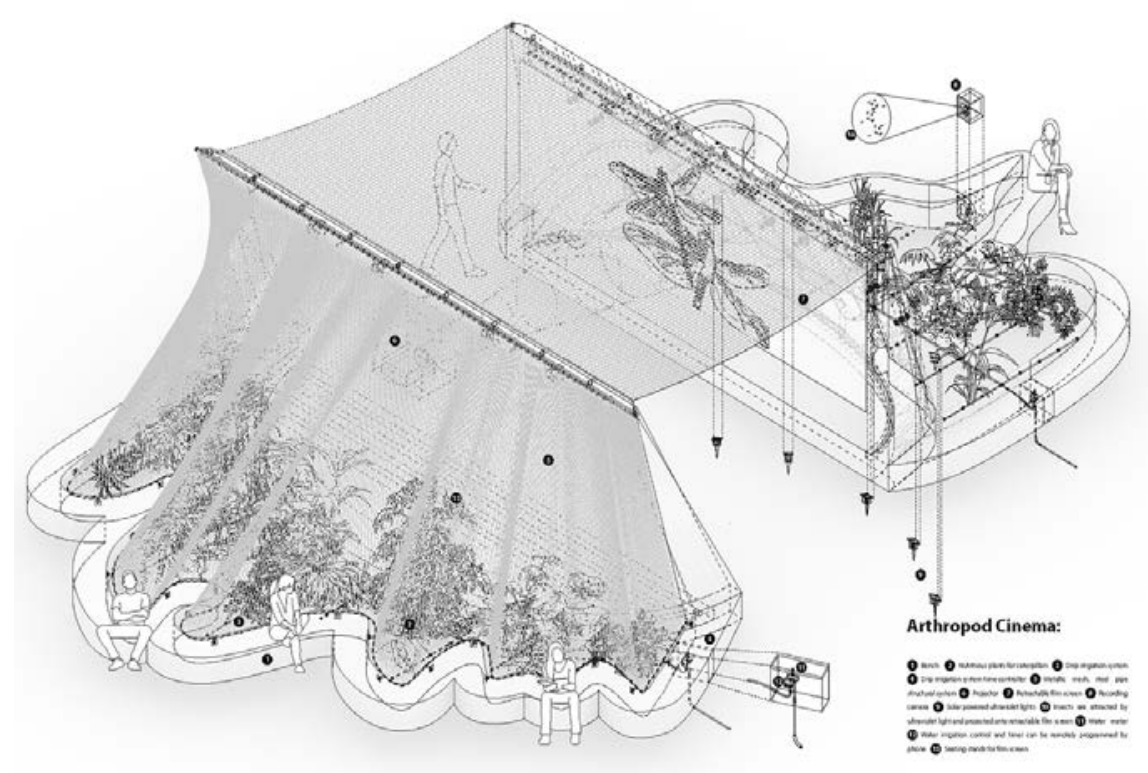

Figure 5

Axonometric

of one of the urban furnishings

including information about selected butterfly species and caterpillars, as well as their nutritious plants (Image by Double Happiness)

Hidden in Plain Sight deploys interior design tactics to both enhance insect habitability, while also increasing people's comfort and provoking human curiosity through new spatial and perceptual experiences. Stemming from the fascinating world of insect vision and perception, the project uses colours, patterns, and light for both insect and human benefit. To provide a sense of camouflage for butterflies, patterns are imprinted on the prototypes' fabric-like curving walls, and colour-coordinating with adjacent wildflowers. To promote habitability by birds, bats, bees, and other insects, distinct 'pods' are fabricated and inserted into the upper portions of the prototype walls, adding a textural and volumetric dimension to the prototypes' undulating surfaces. At night, the design uses the ultraviolet black light to attract insects, a phenomenon that can be video-recorded and projected as a form of spectacle. The aim of Hidden in Plain Sight is to create a sense of shared interiority across species at the heart of an urban environment. 
Figure 6

Perspective of urban furnishings within Matadero

Madrid public spaces. Night performance illustrating envisioned ultraviolet

light spectacle attracting insects (Image by Double Happiness)

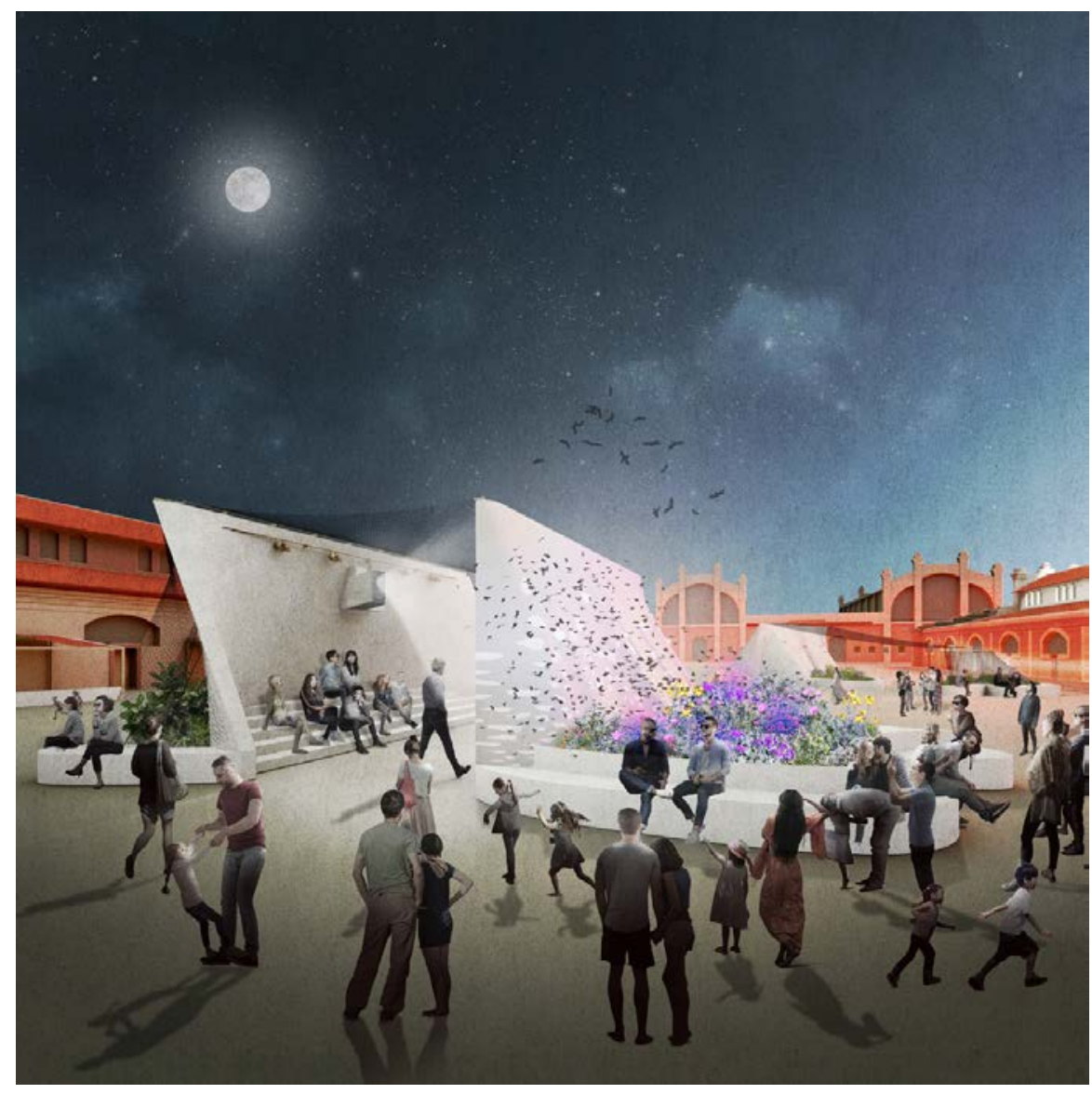

\section{Conclusion}

While exploring how interior design can contribute to raising climate change awareness in the context of public space, both City Creatures and Hidden in Plain Sight seek to also provoke, interrogate, reflect and expand our current understanding of urban occupancy. The world might be a manufactured "grand interior," but, in opposition to historical notions of interiority, it is not exclusively anthropocentric. We know how social inclusion and exclusion in urban environments are spatially constructed. It is clear how minor design details, such as the inclusion of armrests on public benches, prevent homeless populations from sleeping on them, thus contributing to social segregation in our urban interiors. Designers, city representatives and citizens recognise the power of applying interior design tactics in urban public spaces. There is a long history of evidence and literature on how the adequate selection of urban furnishings, pavements and lighting can significantly improve the quality of outdoor urban spaces. A calibrated treatment of outdoor urban space as de-facto public interior can help to foster civic social practices and models of occupation. 
It is time for our disciplinary anthropocentric view on urbanity, as a diverse combination of people from various socioeconomic groups and cultural backgrounds, to be expanded to include a web of interdependent species, both human and non-human. A new and inclusive form of urban interior design could start altering the physiognomy of the city across its multiple nested scales to respond to the recursive relationship between the micro and the macro, between and across species. This paradigm change, from human centred urbanity to a multi-species one might be expedited by raising awareness of the other creatures that also inhabit the city. Promoting a sense of shared interiority, not just among a diverse human population, but between different forms of urban life may contribute to transform public opinion. Interior design tactics can help foster urban intimacy between us, the environment, and the multiple life forms that inhabit it.

\section{Acknowledgement}

The two projects featured in the article City Creatures and Hidden in Plain Sight have been designed in partnership by Double Happiness, a collaboration between the author Nerea Feliz Arrizabalaga (Nerea Feliz Studio) and Joyce Hwang (Ants of the Prairie). Joyce Hwang is Associate Professor and Associate Chair of the Department of Architecture at the University at Buffalo.

\section{References}

Adams, R., \& Marlor, L. (2019). Breaking the binary oppositions of the interior: A momentary permanence. Interiority, 2(2), 113128. https://doi.org/10.7454/in.v2i2.58

Carrington, D. (2019, February 10). Plummeting insect numbers 'threaten collapse of nature.' The Guardian. Retrieved from https://www.theguardian.com/environment/2019/feb/10/ plummeting-insect-numbers-threaten-collapse-of-nature

Geers, K. (2019). Architecture without content. Harvard Design Magazine, 47, 63-64.

Hwang, J. (2013). Living among pests: Designing the biosynthetic city. Next Nature, 35. Retrieved from https://nextnature. net/2013/09/living-among-pests-designing-thebiosynthetic-city

Kaltenbach, C. (2014). Design + insect research. Retrieved from https://kaltenbachlab.ca/design-and-insect-research 
Kaltenbach, C. (2016). Insectarium: Design + insect research lab. Retrieved from https://kaltenbachlab.ca/design-andinsect-research

Meinhold, B. (2010, February 7). Leading architects unveil luxury bug hotels in London. Inhabitat. Retrieved from https:// inhabitat.com/leading-architects-unveil-luxury-bughotels-in-london/

Sloterdijk, P. (2013). In the world interior of capital (W. Hoban, Trans.). Cambridge, MA: Polity Press.

Solomon, J. D. (2018). Public spheres: Hong Kong's interior urbanism. In G. Marinic (Ed.), The interior architecture reader (pp. 414421). New York: Routledge. 